\title{
High-Valent Iron-Oxo Complexes as Dominant Species to Eliminate Pharmaceuticals and Chloride-Containing Intermediates by the Activation of Peroxymonosulfate Under Visible Irradiation
}

\author{
Zhexin Zhu ${ }^{1} \cdot$ Wangyang $\mathrm{Lu}^{1} \cdot$ Tiefeng $\mathrm{Xu}^{1} \cdot \mathrm{Nan} \mathrm{Li}^{1} \cdot$ Gangqiang Wang ${ }^{1} \cdot$ Wenxing Chen ${ }^{1}$
}

Received: 20 September 2019 / Accepted: 18 November 2019 / Published online: 26 November 2019

(C) The Author(s) 2019

\begin{abstract}
Generally, the sulfate $\left(\mathrm{SO}_{4}^{--}\right)$and hydroxyl $\left(\mathrm{HO}^{*}\right)$ radicals are the dominant active species in most catalytic oxidation processes with peroxymonosulfate (PMS). However, the existence of various natural organic and inorganic matters in aquatic environments might influence the oxidation efficiency of these radicals, and/or form more toxic and refractory intermediates than the parent, especially in chlorine-ion-containing conditions. Here, we constructed a novel visible-light catalytic system with PMS based on iron hexadecachlorophthalocyanine-poly (4-vinylpyridine)/polyacrylonitrile nanofibers through pyridine ligands to generate high-valent iron-oxo $(\mathrm{Fe}(\mathrm{IV})=\mathrm{O})$ species as the main active species. The coordination structure was characterized by UV-Vis diffuse reflection, X-ray photoelectron spectroscopy, etc. The high-valent iron-oxo generation from peroxysulfate $\mathrm{O}-\mathrm{O}$ bond heterolytic cleavage was proved by high-definition electrospray ionization mass spectrometer. Ultra-performance liquid chromatography coupled with high-definition mass spectrometry showed that the photocatalytic system was efficient for the degradation of carbamazepine and the chlorinated intermediates by iron-oxo active species in chlorine-ion-containing conditions.
\end{abstract}

Electronic supplementary material The online version of this article (https://doi.org/10.1007/s10562-019-03047-4) contains supplementary material, which is available to authorized users.

Wangyang Lu

luwy@zstu.edu.cn

Wenxing Chen

wxchen@zstu.edu.cn

1 National Engineering Lab for Textile Fiber Materials \&

Processing Technology (Zhejiang), Zhejiang Sci-Tech

University, Hangzhou 310018, China 


\section{Graphic Abstract}

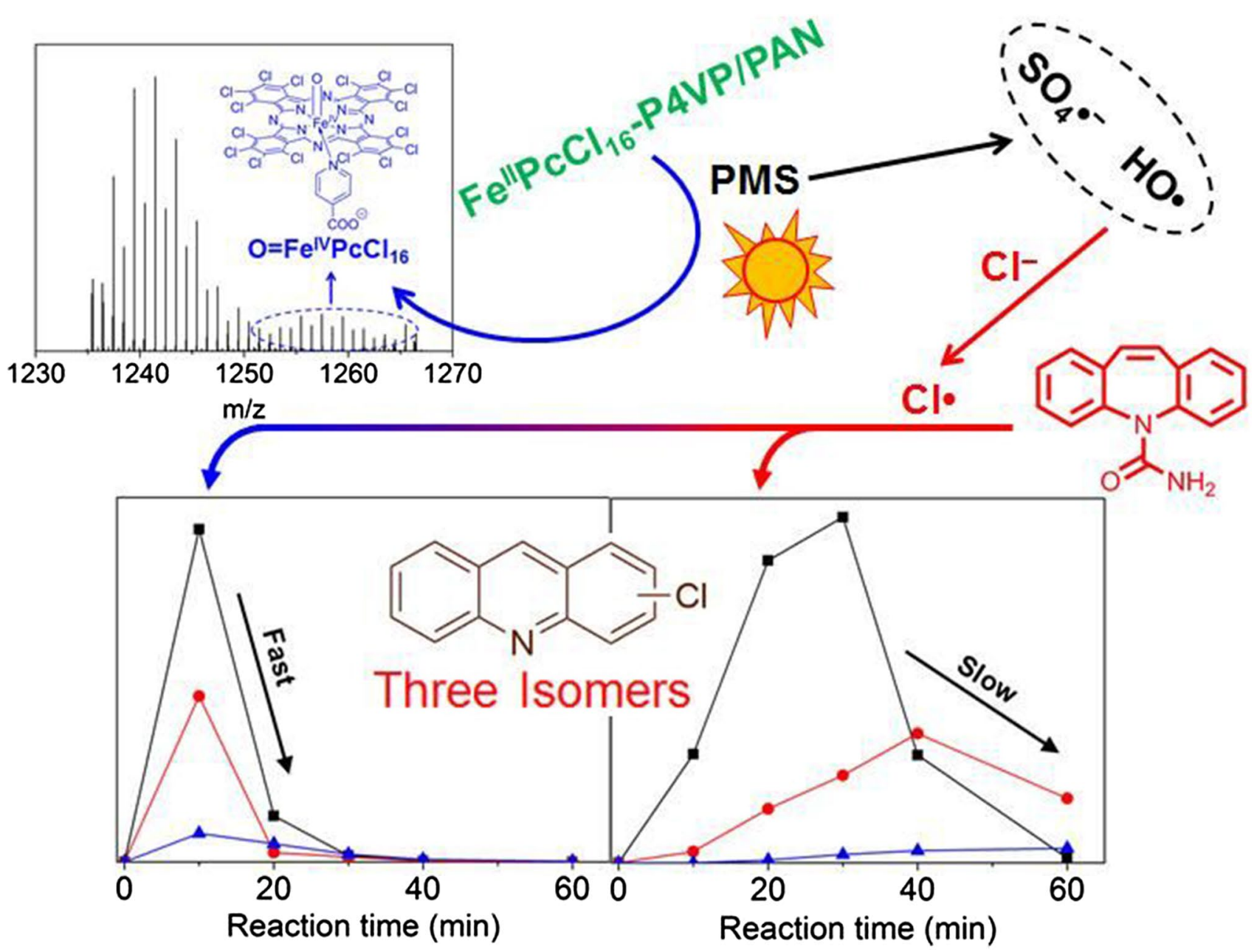

Keywords Visible light $\cdot$ Peroxymonosulfate $\cdot$ High-valency iron-oxo species $\cdot$ Chlorinated intermediates $\cdot$ Degradation pathway

\section{Introduction}

In recent decades, increasing environmental pollution that has resulted from recalcitrant organics, such as pharmaceuticals and their metabolites, personal-care products and endocrine disruptors has obtained increasing attention because of their high persistence and adverse impacts on the ecosystem [1-3]. Advanced-oxidation processes for the destruction of recalcitrant organic contaminants have been applied extensively $[4,5]$. Among the various advanced-oxidation processes, peroxymonosulfate (PMS, $2 \mathrm{KHSO}_{5} \cdot \mathrm{KHSO}_{4} \cdot \mathrm{K}_{2} \mathrm{SO}_{4}$, oxone) as the effective oxidant has been developed gradually since it can generate hydroxyl $\left(\mathrm{HO}^{\circ}\right)$ and sulfate $\left(\mathrm{SO}_{4}^{-}\right)$radicals that improve the flexibility over a broad $\mathrm{pH}$ range [6-8]. To generate such radicals, numerous activators have been investigated, including ultraviolet (UV) [9], transition metals
[10-12], ultrasound [13], electrochemical activation [14] and carbon catalysts [15]. Although $\mathrm{HO}^{-}$and $\mathrm{SO}_{4}^{--}$have a strong oxidizing capability because of their high redox potential $[16,17]$, ubiquitous natural organic/inorganic matters in aquatic ecosystems will influence its oxidizing capacity and form byproducts that may be more toxic and refractory than the parent $[14,18]$. In particular, the chlorine ion, which can be oxidized by sulfate radicals to form active chlorine species $\mathrm{HOCl} / \mathrm{Cl}_{2}$ or chlorine radicals that may cause the occurrence of chlorinated intermediates, as a usual inorganic ion, exist in a variety of aquatic environments [19-22]. Thus, it is necessary not to overlook the transformation products and pollutant pathways.

Metalloporphyrins (MPs) as the key catalytic structures in biological enzymes activate $\mathrm{O}_{2}$ or other peroxide to react with substrates under mild conditions [23-25]. 
Metallophthalocyanines (MPcs) are attractive as catalysts for analogous structures with MP complexes and because of their cost-effective and simple preparation [26]. MPcs exhibit a better spectral response in the visible-light region compared with MPs that can be applied widely in the photocatalytic field $[27,28]$. Iron phthalocyanine (FePc) and its numerous derivatives with various substituent groups as environmentally friendly catalysts have been applied extensively in catalytic reactions [29-31]. Iron hexadecachlorophthalocyanine $\left(\mathrm{FePcCl}_{16}\right)$ is one of the stable derivatives because of the macrocyclic structure was protected by chlorinated substituents at the peripheries due to their strong electron-withdrawing. However, the limitation of $\mathrm{FePcCl}_{16}$ is applied in aqueous solution because of its catalytically inactive dimers [32], which could be overcome by the supported catalytic systems [26]. In previous studies, several general approaches (e.g., physical adsorption, physical mixing, covalent anchoring, electrostatic interaction, coordination bonding) have been used to immobilize MPcs on various supports to improve stability and cyclic performance, such as polymers [33, 34], carbon nanotubes [35-37], carbon fiber [38], graphitic carbon nitride [39-41], cellulose [42-44] and mesoporous carbon [45]. In various $\mathrm{MPc}$-supported catalysts, $\mathrm{HO}^{*} / \mathrm{SO}^{-{ }^{-}}$as the main species from homolytic cleavage of the peroxide $\mathrm{O}-\mathrm{O}$ bond to remove recalcitrant organic contaminants. High-valence metal-oxo species are generated from the heterolytic cleavage of the peroxide $\mathrm{O}-\mathrm{O}$ bond and compete with the homolytic cleavage process, which have been recognized as active species in enzymatic processes [46].

We used poly (4-vinylpyridine) (P4VP)/polyacrylonitrile (PAN) nanofibers (NF) (P4VP/PAN NFs), which were prepared in our previous work [33], to immobilize $\mathrm{FePcCl}_{16}$ by the nitrogen atom of the pyridinyl moieties of P4VP to synthesize $\mathrm{FePcCl}_{16}$-P4VP/PAN NFs.
Carbamazepine (CBZ) as the most frequently detected recalcitrant organic in aquatic environments to evaluate the catalytic ability at neutral $\mathrm{pH}$. The intermediates and degradation pathway of CBZ was proposed by ultraperformance liquid chromatography (UPLC) coupled with high-definition mass spectrometry (HDMS). When $\mathrm{NaCl}$ was introduced, $\mathrm{FePcCl}_{16}-\mathrm{P} 4 \mathrm{VP} / \mathrm{PAN} \mathrm{NFs} / \mathrm{PMS} /$ visible-light and PMS/visible-light systems showed an excellent catalytic activity for CBZ decomposition. The $\mathrm{FePcCl}_{16}-\mathrm{P} 4 \mathrm{VP} / \mathrm{PAN} \mathrm{NF} / \mathrm{PMS} / \mathrm{NaCl} / \mathrm{visible}$-light system could degrade $\mathrm{CBZ}$ and its transformation products rapidly and completely, including the chlorinated intermediates. However, in the PMS/NaCl/visible-light system, residual chlorinated intermediates were still observed. The reason for this phenomenon is that, in the $\mathrm{FePcCl}_{16}$-P4VP/PAN $\mathrm{NFs} / \mathrm{PMS} / \mathrm{NaCl} /$ visible-light system, visible-light-induced $\mathrm{FePcCl}_{16}$ and the electron donors of pyridine were identified as major factors in the formation of $\mathrm{Fe}(\mathrm{IV})=\mathrm{O}$ species, which could efficiently degrade chlorinated intermediates from CBZ.

\section{Materials and Methods}

\subsection{Materials and Reagents}

$\mathrm{FePcCl}_{16}$ was prepared by previously reported method [47]. All other chemicals used have been described in a previous study [33].

\subsection{Preparation of P4VP/PAN Nanofibers (P4VP/ PAN NFs)}

A detailed method has been described in a previous study [33].
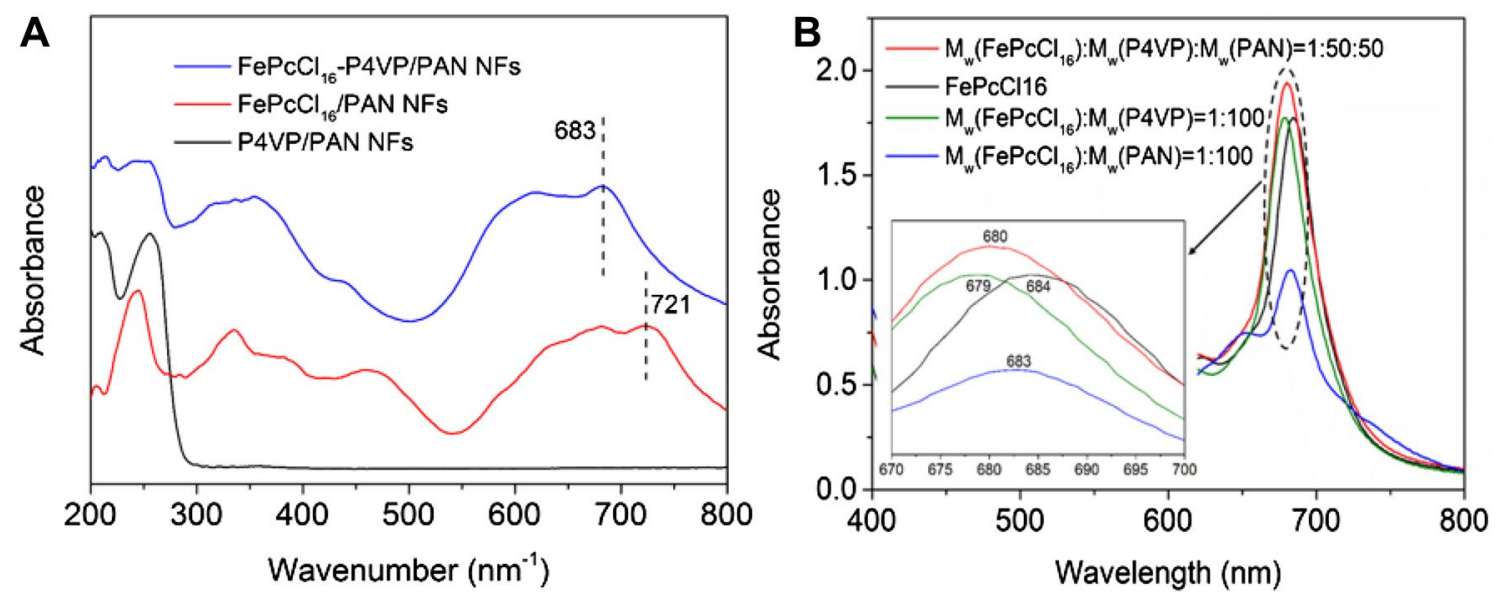

Fig. 1 a UV-Vis diffuse reflection spectra of $\mathrm{FePcCl}_{16}$-P4VP/PAN NFs, $\mathrm{FePcCl}_{16} / \mathrm{PAN} \mathrm{NFs}$ and P4VP/PAN NFs. b UV-vis spectral of $\mathrm{FePcCl}_{16} / \mathrm{P} 4 \mathrm{VP}, \mathrm{FePcCl}_{16} / \mathrm{P} 4 \mathrm{VP} / \mathrm{PAN}, \mathrm{FePcCl}_{16} / \mathrm{PAN}$ and $\mathrm{FePcCl}_{16}$ DMF solution 

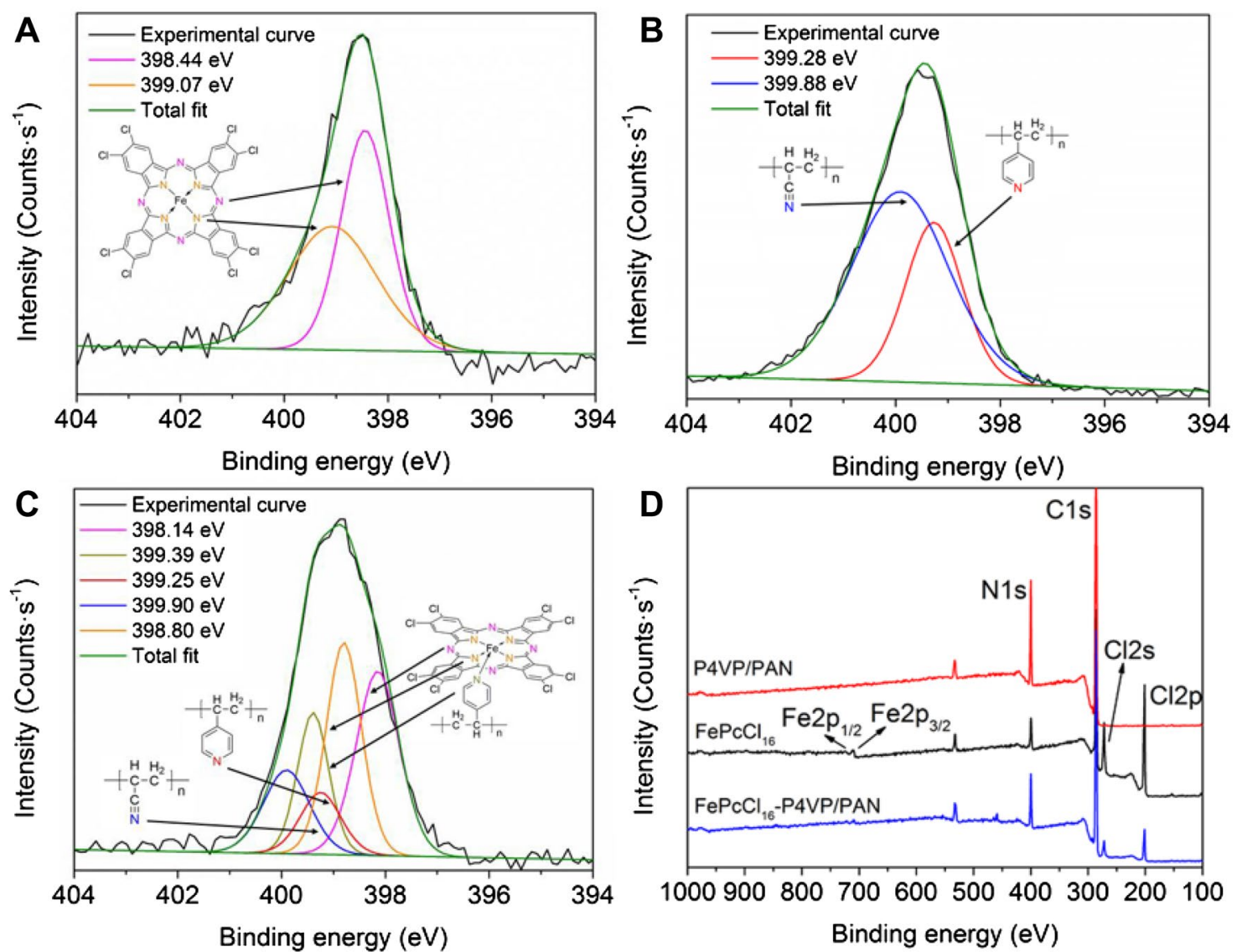

Fig. 2 a Curve fit of $\mathrm{N} 1 s$ peak of $\mathrm{FePcCl}_{16}$, b P4VP/PAN NFs, $\mathbf{c} \mathrm{FePcCl}_{16}-\mathrm{P} 4 \mathrm{VP} / \mathrm{PAN}$ NFs and $\mathbf{d}$ survey XPS for P4VP/PAN NFs, FePcCl 16 and $\mathrm{FePcCl}_{16}$-P4VP/PAN NFs

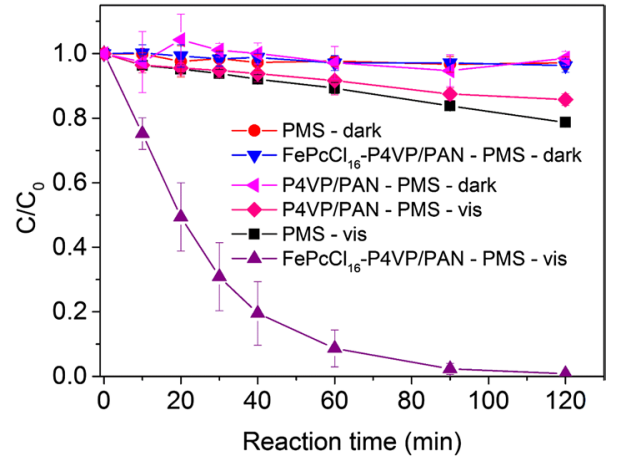

Fig. 3 Degradation of $\mathrm{CBZ}$ with or without $\mathrm{FePcCl}_{16}-\mathrm{P} 4 \mathrm{VP} / \mathrm{PAN}$ NFs or P4VP/PAN NFs under visible light irradiation $(\lambda>420 \mathrm{~nm})$ and in dark. $\left[\mathrm{FePcCl}_{16}\right.$-P4VP/PAN NFs] $=0.3 \mathrm{~g} / \mathrm{L}, \quad[\mathrm{P} 4 \mathrm{VP} / \mathrm{PAN}$ $\mathrm{NFs}]=0.3 \mathrm{~g} / \mathrm{L},[\mathrm{CBZ}]=0.025 \mathrm{mM},[\mathrm{PMS}]=2 \mathrm{mM}, \mathrm{pH} 7$

\subsection{Preparation of $\mathrm{FePcCl}_{16}-\mathrm{P} 4 \mathrm{VP} / \mathrm{PAN}$ Nanofibers (FePcCl ${ }_{16}-\mathrm{P} 4 \mathrm{VP} / \mathrm{PAN}$ NFs)}

$\mathrm{FePcCl}_{16}$ (15 wt $\% \mathrm{FePcCl}_{16}$ vs. P4VP/PAN NFs) was dispersed in anhydrous tetrahydrofuran (THF) according to the

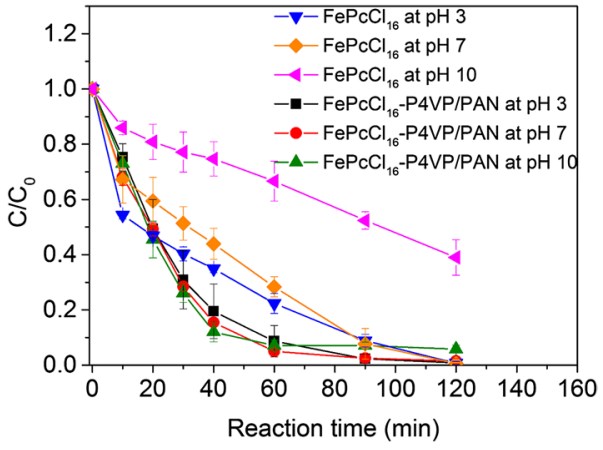

Fig. 4 Effect of $\mathrm{pH}$ on degradation of $\mathrm{CBZ}$ by $\mathrm{FePcCl}_{16}$ and $\mathrm{FePcCl}_{16}$-P4VP/PAN NFs under visible light irradiation $(\lambda>420 \mathrm{~nm}) . \quad\left[\mathrm{FePcCl}_{16}\right]=0.045 \mathrm{~g} / \mathrm{L}, \quad\left[\mathrm{FePcCl}_{16}-\mathrm{P} 4 \mathrm{VP} / \mathrm{PAN}\right.$ $\mathrm{NFs}]=0.3 \mathrm{~g} / \mathrm{L},[\mathrm{CBZ}]=0.025 \mathrm{mM},[\mathrm{PMS}]=2 \mathrm{mM}$

detailed method as described previously [33]. Figure S1 shows the preparation method of the FePcCl16-P4VP/PAN NFs. The content of $\mathrm{FePcCl}_{16}$ in $\mathrm{FePcCl}_{16}$-P4VP/PAN NFs based on inductively-coupled plasma (ICP) results (Optima 2100DV), which was $1.029 \times 10^{-4} \mathrm{~mol} / \mathrm{g}$. 


\subsection{Characterization}

ATR-FTIR spectroscopy, XPS, UV-Vis analysis and UV-Vis diffuse reflection spectra were used to detect the structure of $\mathrm{FePcCl}_{16}$ powders, $\mathrm{P} 4 \mathrm{VP} / \mathrm{PAN} \mathrm{NFs}$ and $\mathrm{FePCCl}_{16}$-P4VP/PAN NFs. Detailed parameters have been described in the literature [36]. The morphology of catalytic fibers were observed by VHX-2000 digital microscope (Keyence, Japan).

\subsection{Photocatalytic Experiments}

The detailed photocatalytic experiments were referenced our previous work [39]. All experiments were conducted in a $40-\mathrm{mL}$ glass vessels at room temperature. The vessels contained $0.3 \mathrm{~g} / \mathrm{L}$ catalytic NFs with an initial CBZ concentration of $0.025 \mathrm{mM}$ and PMS of $2 \mathrm{mM}$. The sample preparation and the measurements is provided in the Supplementary Material.

\section{Results and Discussion}

\subsection{Characterization}

Figure 1a shows the UV-Vis diffuse reflectance spectra of the P4VP/PAN NFs, FePcCl 16 /PAN NFs and
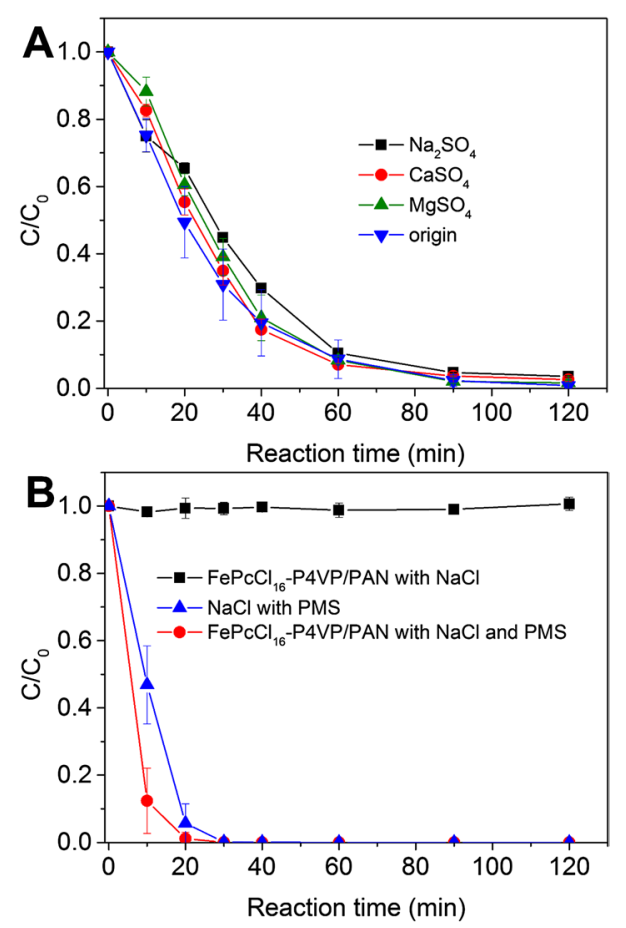

Fig. 5 Effect of inorganic ions $\mathbf{a ~ N a}{ }^{+}, \mathrm{Mg}^{2+}, \mathrm{Ca}^{2+}$ and $\mathbf{b ~} \mathrm{Cl}^{-}$on degradation of $\mathrm{CBZ}$ by $\mathrm{FePcCl}_{16}$-P4VP/PAN NFs under visible light irradiation $(\lambda>420 \mathrm{~nm}) .\left[\mathrm{Na}^{+}\right]=\left[\mathrm{Mg}^{2+}\right]=\left[\mathrm{Ca}^{2+}\right]=\left[\mathrm{Cl}^{-}\right]=10 \mathrm{mM}$; $\left[\mathrm{FePcCl}_{16}-\mathrm{P} 4 \mathrm{VP} / \mathrm{PAN} \quad \mathrm{NFs}\right]=0.3 \mathrm{~g} / \mathrm{L}, \quad[\mathrm{CBZ}]=0.025 \mathrm{mM}$, $[\mathrm{PMS}]=2 \mathrm{mM}, \mathrm{pH} 7$
$\mathrm{FePcCl}_{16}-\mathrm{P} 4 \mathrm{VP} / \mathrm{PAN}$ NFs. In the visible region, a strong absorption band of FePcCl16/PAN NFs at $721 \mathrm{~nm}$ was observed. The absorption band of $\mathrm{FePcCl}_{16}-\mathrm{P} 4 \mathrm{VP} / \mathrm{PAN} \mathrm{NFs}$ was blue-shifted by $\sim 38 \mathrm{~nm}$, which may because of a ligandto-metal charge-transfer transformation from the pyridine of P4VP toward the metal atom of $\mathrm{FePcCl}_{16}$ [48]. The digital microscope images of $\mathrm{FePcCl}_{16}$-P4VP/PAN NFs (Fig. S2A) and P4VP/PAN NFs (Fig. S2B) show that $\mathrm{FePcCl}_{16}$ powders loaded on P4VP/PAN NFs.

Figure $1 \mathrm{~b}$ showed the UV-Vis absorption spectra of P4VP, PAN and $\mathrm{FePcCl}_{16}$ in DMF solution. $\mathrm{FePcCl}_{16}$ showed a Q-band at $684 \mathrm{~nm}$. In contrast, the maximum absorption of the $\mathrm{FePcCl}_{16} / \mathrm{P} 4 \mathrm{VP}$ and $\mathrm{FePcCl}_{16} / \mathrm{P} 4 \mathrm{VP} /$ PAN were blue-shifted by $\sim 5 \mathrm{~nm}$ and $\sim 4 \mathrm{~nm}$, respectively, whereas $\mathrm{FePcCl}_{16} / \mathrm{PAN}$ was shifted by $\sim 1 \mathrm{~nm}$ only, which indicates the coordination between the $\mathrm{FePcCl}_{16}$ and P4VP.

XPS was used to investigate the chemical state and surface composition between $\mathrm{FePcCl}_{16}$ and P4VP/PAN NFs. As shown in Fig. 2d, the survey spectra of a wide scan showed that new bands of iron and chlorine were observed when $\mathrm{FePcCl}_{16}$ was supported on P4VP/PAN NFs. The $\mathrm{N} 1 s$ core-level spectrum of the $\mathrm{FePcCl}_{16}$ has two distinct peaks centered at $398.44 \mathrm{eV}$ and $399.07 \mathrm{eV}$, which are assigned to the $\mathrm{C}-\mathrm{N}=\mathrm{C}$ and $\mathrm{C}-\mathrm{N}-\mathrm{C}$ bonds of $\mathrm{FePcCl}_{16}$ (Fig. 2a). $399.28 \mathrm{eV}$ and $399.88 \mathrm{eV}$ are attributed to the imine moiety $(-\mathrm{N}=)$ of the pyridine rings [49] and the $\mathrm{C} \equiv \mathrm{N}$ of PAN [50], respectively (Fig. 2b). After the interaction of $\mathrm{FePcCl}_{16}$ and P4VP/PAN NFs, the peak for the $\mathrm{C}-\mathrm{N}=\mathrm{C}$ and $\mathrm{C}-\mathrm{N}-\mathrm{C}$ bonds of $\mathrm{FePcCl}_{16}$ moved to $398.14 \mathrm{eV}$ and $398.80 \mathrm{eV}$, respectively, and the imine moiety $(-\mathrm{N}=)$ of the pyridine rings moved to $399.39 \mathrm{eV}$, whereas the $\mathrm{C} \equiv \mathrm{N}$ of PAN was unchanged (Fig. 2c). It is because that the pyridine rings in the P4VP as the electron donors rather than the $\mathrm{C} \equiv \mathrm{N}$ groups to coordinate with $\mathrm{FePcCl}_{16}$ [48]. According to the TEM images of P4VP/PAN NFs (Fig. S3A, B) and $\mathrm{FePcCl}_{16}-\mathrm{P} 4 \mathrm{VP} / \mathrm{PAN}$ NFs (Fig. S3C, D), after FePcCl${ }_{16}$ loaded on $\mathrm{P} 4 \mathrm{VP} / \mathrm{PAN}$ NFs, the textural properties are maintained and $\mathrm{FePcCl}_{16}$ are well dispersed on P4VP/PAN NFs.

\subsection{Photocatalytic Activity}

CBZ was selected as the model pollutant to detect the catalytic properties of $\mathrm{FePcCl}_{16}-\mathrm{P} 4 \mathrm{VP} / \mathrm{PAN}$ NFs. The influence of PMS dosage is shown in Fig. S5. The $\mathrm{FePcCl}_{16}-\mathrm{P} 4 \mathrm{VP} /$ PAN NFs could not degrade CBZ without PMS under visible-light irradiation. With an increase in PMS concentration, the removal rate of $\mathrm{CBZ}$ increased. When the concentration of PMS was $2 \mathrm{mM}, \mathrm{FePcCl}_{16}-\mathrm{P} 4 \mathrm{VP} / \mathrm{PAN}$ NFs exhibited the highest photocatalytic activity. Therefore, in this study, $2 \mathrm{mM}$ PMS was selected to explore the photocatalytic activity of $\mathrm{FePcCl}_{16}-\mathrm{P} 4 \mathrm{VP} / \mathrm{PAN}$ NFs. As show in Fig. $3 \mathrm{CBZ}$ did not decrease in the presence of $\mathrm{FePcCl}_{16}$-P4VP/PAN NFs with PMS in the dark, which indicates that CBZ cannot 

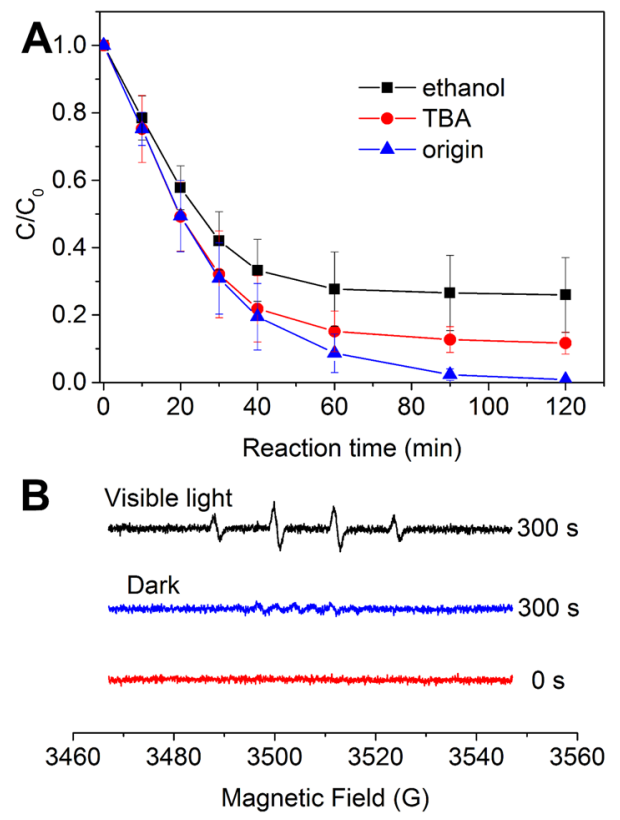

Fig. 6 a Effect of TBA and ethanol on degradation of CBZ by $\mathrm{FePcCl}_{16}$-P4VP/PAN NFs under visible light irradiation $(\lambda>420 \mathrm{~nm}) . \quad\left[\mathrm{FePcCl}_{16}\right.$-P4VP/PAN NFs] $=0.3 \mathrm{~g} / \mathrm{L}$, $[\mathrm{CBZ}]=0.025 \mathrm{mM},[\mathrm{PMS}]=2 \mathrm{mM},[\mathrm{TBA}]=[$ ethanol $]=200 \mathrm{mM}$; $\mathrm{pH} 7$; $\mathbf{b}$ DMPO spin-trapping EPR spectra in aqueous solution in the presence of $\mathrm{FePcCl}_{16}-\mathrm{P} 4 \mathrm{VP} / \mathrm{PAN}$ NFs and PMS (2 mM) with DMPO $(10 \mathrm{mM})$

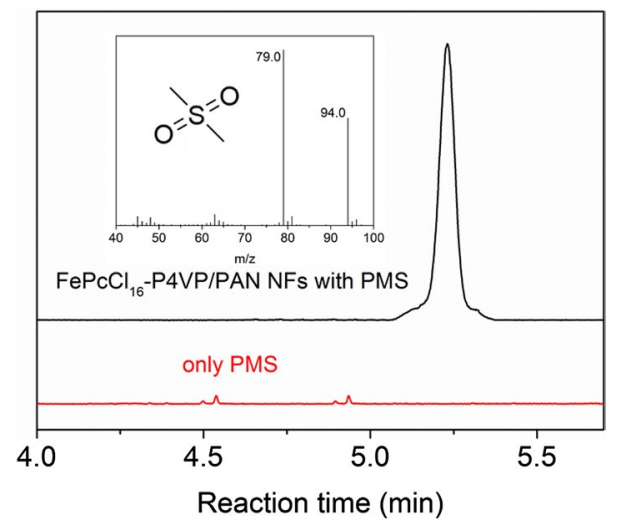

Fig. 7 GC-MS chromatogram of photocatalytic oxidation products of DMSO $(10 \mathrm{mM})$ catalyzed with and without $\mathrm{FePcCl}_{16}-\mathrm{P} 4 \mathrm{VP} /$ PAN NFs $(0.3 \mathrm{~g} / \mathrm{L})$ under visible light irradiation $(\lambda>420 \mathrm{~nm})$, $[\mathrm{PMS}]=2 \mathrm{mM}$, [ethanol] $=1 \mathrm{M} ; \mathrm{pH}$ 7. The inset shows the MS spectrum of $\mathrm{DMSO}_{2}$

be removed without visible-light irradiation. PMS cannot degrade CBZ in the dark. Only P4VP/PAN NFs also cannot activate PMS for degrading CBZ. When visible light was introduced in the reaction, approximately $20 \% \mathrm{CBZ}$ was removed in the presence of PMS alone and $\sim 97 \% \mathrm{CBZ}$ was removed with $\mathrm{FePcCl}_{16}-\mathrm{P} 4 \mathrm{VP} / \mathrm{PAN}$ NFs and PMS, which implies that $\mathrm{FePcCl}_{16}$-P4VP/PAN NFs could activate PMS to degrade $\mathrm{CBZ}$ under visible-light irradiation.

The $\mathrm{pH}$ is a non-negligible factor in the degradation of organic contaminants in aqueous solution. Here, we researched the photocatalytic oxidation of CBZ with PMS, $\mathrm{FePcCl}_{16} / \mathrm{PMS}$ and $\mathrm{FePcCl}_{16}$-P4VP/PAN NFs/PMS under visible-light irradiation at $\mathrm{pH} 3,7$ and 10. Figure 4 shows a good photocatalytic activity in the $\mathrm{FePcCl}_{16} / \mathrm{PMS} /$ visiblelight system at $\mathrm{pH} 3$ and 7, whereas it possesses a relatively weak photocatalytic capacity at $\mathrm{pH} 10$. This system is a Fenton-like catalytic system, which produces $\mathrm{SO}_{4}^{--}$and $\mathrm{HO}^{\circ}$ radicals as the dominant species. And high $\mathrm{pH}$ could inhibit the reaction ability of $\mathrm{SO}_{4}^{--}$and $\mathrm{HO}^{\circ}$ radicals [51]. In the $\mathrm{FePcCl}_{16}-\mathrm{P} 4 \mathrm{VP} / \mathrm{PAN} \mathrm{NF} / \mathrm{PMS} /$ visible-light system, CBZ was removed almost completely after $120 \mathrm{~min}$ at $\mathrm{pH} 3,7$ and 10. The results indicate that $\mathrm{FePcCl}_{16}-\mathrm{P} 4 \mathrm{VP} /$ PAN NFs exhibited an excellent photocatalytic ability over a broader $\mathrm{pH}$ range than pure $\mathrm{FePcCl}_{16}$. The results show that $\mathrm{FePcCl}_{16}$ anchored on P4VP/PAN NFs may lead to a unique photocatalytic mechanism that differs from $\mathrm{FePcCl}_{16}$.

Inorganic salts usually exist in practical wastewater and may influence the pollutant-oxidation performance [52]. Hence, the impact of inorganic salts is necessary to evaluate the $\mathrm{FePcCl}_{16}-\mathrm{P} 4 \mathrm{VP} / \mathrm{PAN} \mathrm{NFs} / \mathrm{PMS} /$ visible-light system. There was no obvious influence on the degradation of CBZ in the $\mathrm{FePcCl}_{16}-\mathrm{P} 4 \mathrm{VP} / \mathrm{PAN}$ NFs/PMS/visible-light system in the presence of inorganic salts $\left(\mathrm{Na}_{2} \mathrm{SO}_{4}, \mathrm{CaSO}_{4}\right.$ and $\left.\mathrm{MgSO}_{4}\right)$ (Fig. 5a). The influence of $\mathrm{NaHCO}_{3}$ and $\mathrm{Na}_{3} \mathrm{PO}_{4}$ was in Fig. S6. The removal rate of CBZ was slightly inhibited by $\mathrm{Na}_{3} \mathrm{PO}_{4}$ and inhibited by $\mathrm{NaHCO}_{3}$ severely. Except for the aforementioned ions, chloride ion $\left(\mathrm{Cl}^{-}\right)$is another major inorganic anion in water resources and almost all natural waters. When $\mathrm{NaCl}$ is introduced in the $\mathrm{FePcCl}_{16}-\mathrm{P} 4 \mathrm{VP} /$ PAN NFs/PMS/visible-light system, as shown in Fig. 5b, the removal rate increased significantly and CBZ almost degraded completely in $\sim 20 \mathrm{~min}$. Without visible light, $\mathrm{NaCl}$ could not promote adsorption and the catalytic ability of $\mathrm{FePcCl}_{16}-\mathrm{P} 4 \mathrm{VP} / \mathrm{PAN}$ NFs. Only PMS with $\mathrm{NaCl}$ under visible light could accelerate the degradation of CBZ. Based on the aforementioned phenomenon, the addition of $\mathrm{NaCl}$ would promote the photocatalytic degradation of CBZ with PMS, and $\mathrm{FePcCl}_{16}-\mathrm{P} 4 \mathrm{VP} / \mathrm{PAN}$ NFs led to a greater promotion effect. According to the literature [19, 20], PMS and sulfate radicals can oxidize chloride ions to active chlorine species $\mathrm{HOCl} / \mathrm{Cl}_{2}$ or chlorine radicals under visible light, which can degrade CBZ rapidly. In addition to the aforementioned radicals, other catalytic mechanisms may exist in the $\mathrm{FePcCl}_{16}-\mathrm{P} 4 \mathrm{VP} / \mathrm{PAN} \mathrm{NFs} / \mathrm{PMS} / \mathrm{Cl}^{-} /$visible-light system that promote the removal rate further.

Recycling experiments were conducted with the $\mathrm{FePcCl}_{16}-\mathrm{P} 4 \mathrm{VP} / \mathrm{PAN}$ NFs/PMS system under visiblelight irradiation (Fig. S7). After six reaction cycles, the 


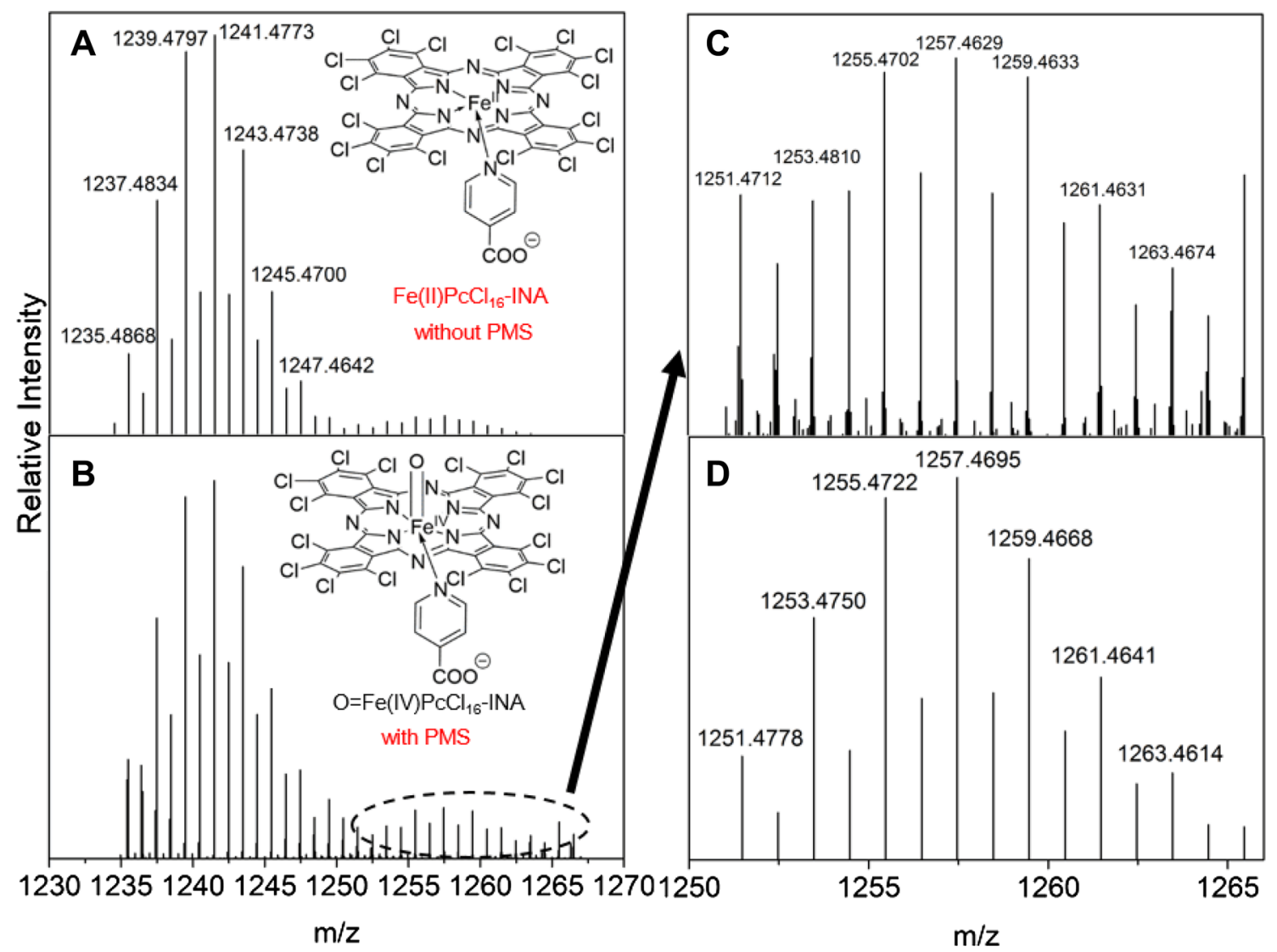

Fig. 8 High-definition electrospray mass spectra of complex $\mathrm{FePcCl}_{16}$-INA without PMS (a) and with PMS under visible light (b); enlarge the mass spectra of $\mathrm{O}=\mathrm{FePcCl}_{16}$-INA (c) and theoretical mass spectrum of $\mathrm{O}=\mathrm{FePcCl}_{16}$-INA (d)

photocatalytic ability of $\mathrm{FePcCl}_{16}$-P4VP/PAN NFs had not weakened. The degradation of other organic contaminants is listed in Table S1.

\subsection{Mechanism Analysis}

PMS could be activated by visible light to produce $\mathrm{SO}_{4}^{--}$and $\mathrm{HO}^{\circ}$ radicals $[18,53]$. TBA and ethanol are as the quencher of $\mathrm{SO}_{4}^{--}$and $\mathrm{HO}^{\circ}[39,54]$. The $\mathrm{HO}^{\circ}$ can be quenched by ethanol and TBA, whereas the $\mathrm{SO}_{4}^{--}$can be quenched only by ethanol. Ethanol could quenched both $\mathrm{SO}_{4}^{--}$and $\mathrm{HO}$, whereas TBA quenched $\mathrm{SO}_{4}^{-}$only. Thus, the difference in $\mathrm{CBZ}$ degradation rates in the $\mathrm{FePcCl}_{16}$-P4VP/PAN NFs/ PMS system under visible light in existence of ethanol and TBA to identify the contribution of the two radicals. The influence of two quenchers of CBZ degradation efficiency was showed in Fig. 6a. Removal rates of CBZ without quencher was $\sim 98 \%$, whereas the corresponding values in existence of TBA decreased by $\sim 15 \%$ and ethanol decreased by $\sim 30 \%$, respectively. These results suggest that only $30 \%$ removal of $\mathrm{CBZ}$ was contributed by $\mathrm{HO}^{\circ}$ and $\mathrm{SO}_{4}^{--}$, and other oxidation processes existed in the $\mathrm{FePcCl}_{16}-\mathrm{P} 4 \mathrm{VP} /$ PAN NFs/PMS/visible-light system as the dominant agent of $70 \%$ CBZ degradation. No obvious EPR signals existed for the $\mathrm{FePcCl}_{16}-\mathrm{P} 4 \mathrm{VP} / \mathrm{PAN}$ NFs/PMS system in the dark (Fig. 6b). Under visible light after $300 \mathrm{~s}$, DMPO-OH signals were observed. However, we could not detect the DMPO$\mathrm{SO}_{4}$ signals. $\mathrm{SO}_{4}^{-}$radicals may not be stable in aqueous solution, but these react with $\mathrm{H}_{2} \mathrm{O}$ to form $\mathrm{HO}^{\circ}$ radicals [55].

GC-MS and HDMS were used to investigate other potent active species. Sulfoxides can be oxidized by the two-electron transfer step from $\mathrm{Fe}(\mathrm{IV})=\mathrm{O}$ species to produce the corresponding sulfones (Eq. 1), which differ from the $\mathrm{HO}^{\circ}$ products (Eq. 2), and the $\mathrm{SO}_{4}^{--}$products are similar to the $\mathrm{HO}^{*}$ products $[39,56]$. 


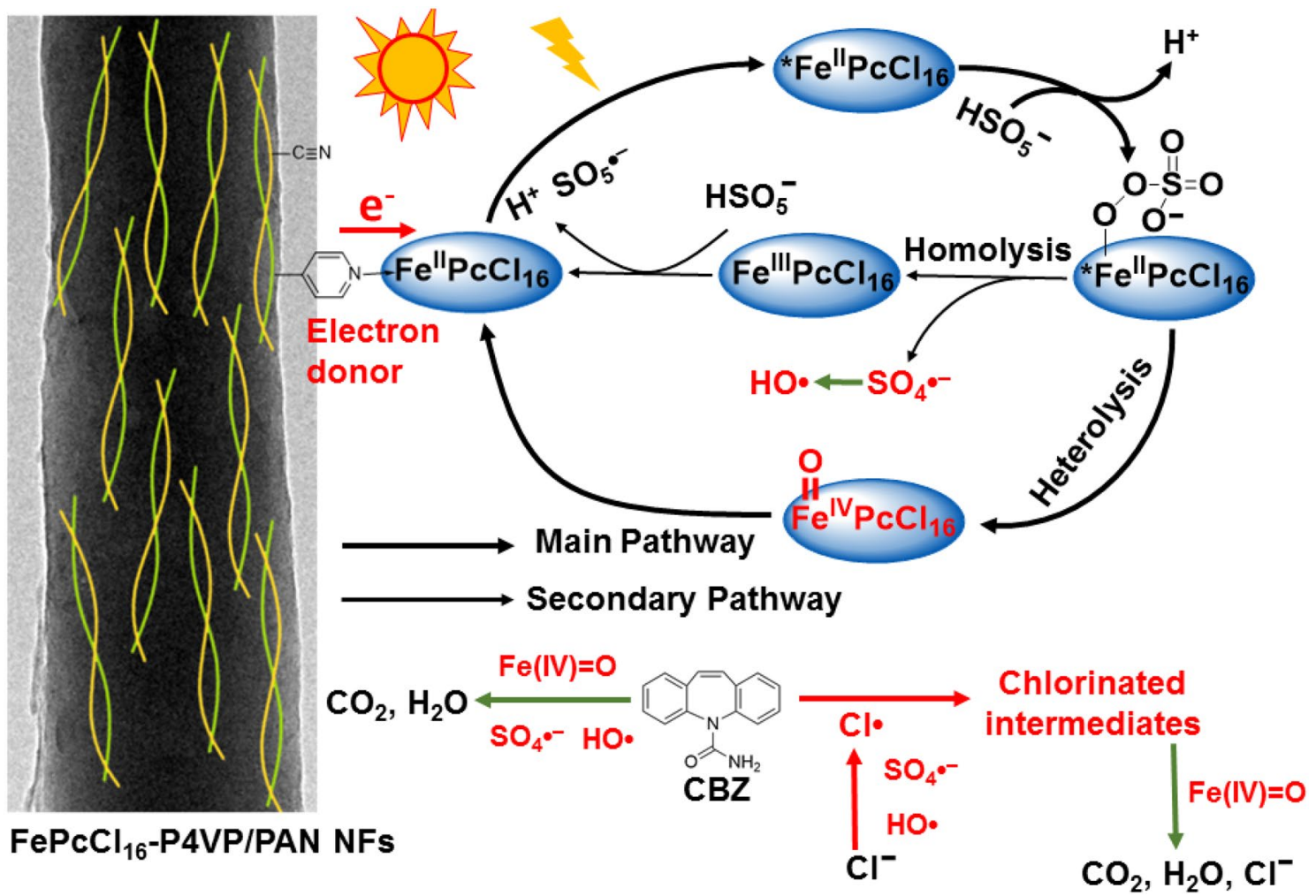

Fig. 9 Proposed pathway for the formation of active species in $\mathrm{FePcCl}_{16}-\mathrm{P} 4 \mathrm{VP} / \mathrm{PAN}$ NFs/PMS system under visible light irradiation $(\lambda>420 \mathrm{~nm})$
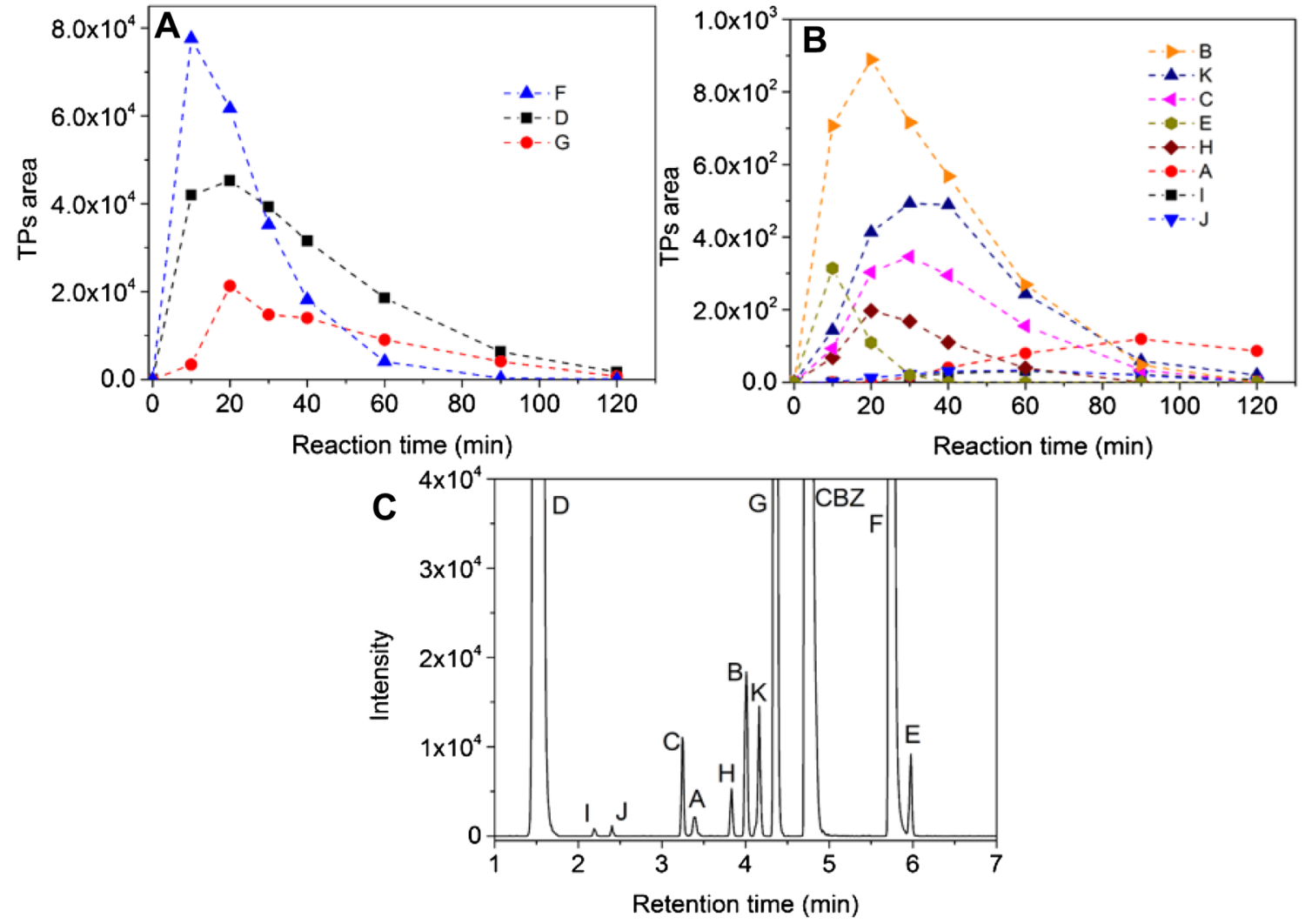

Fig. 10 Reaction over time of main transformation products area (a, b) and TIC of CBZ degradation (c) by $\mathrm{FePcCl}_{16}-\mathrm{P} 4 \mathrm{VP} / \mathrm{PAN}$ NFs in the presence of PMS at $\mathrm{pH} 7$ under visible light irradiation $(\lambda>420 \mathrm{~nm})$ 

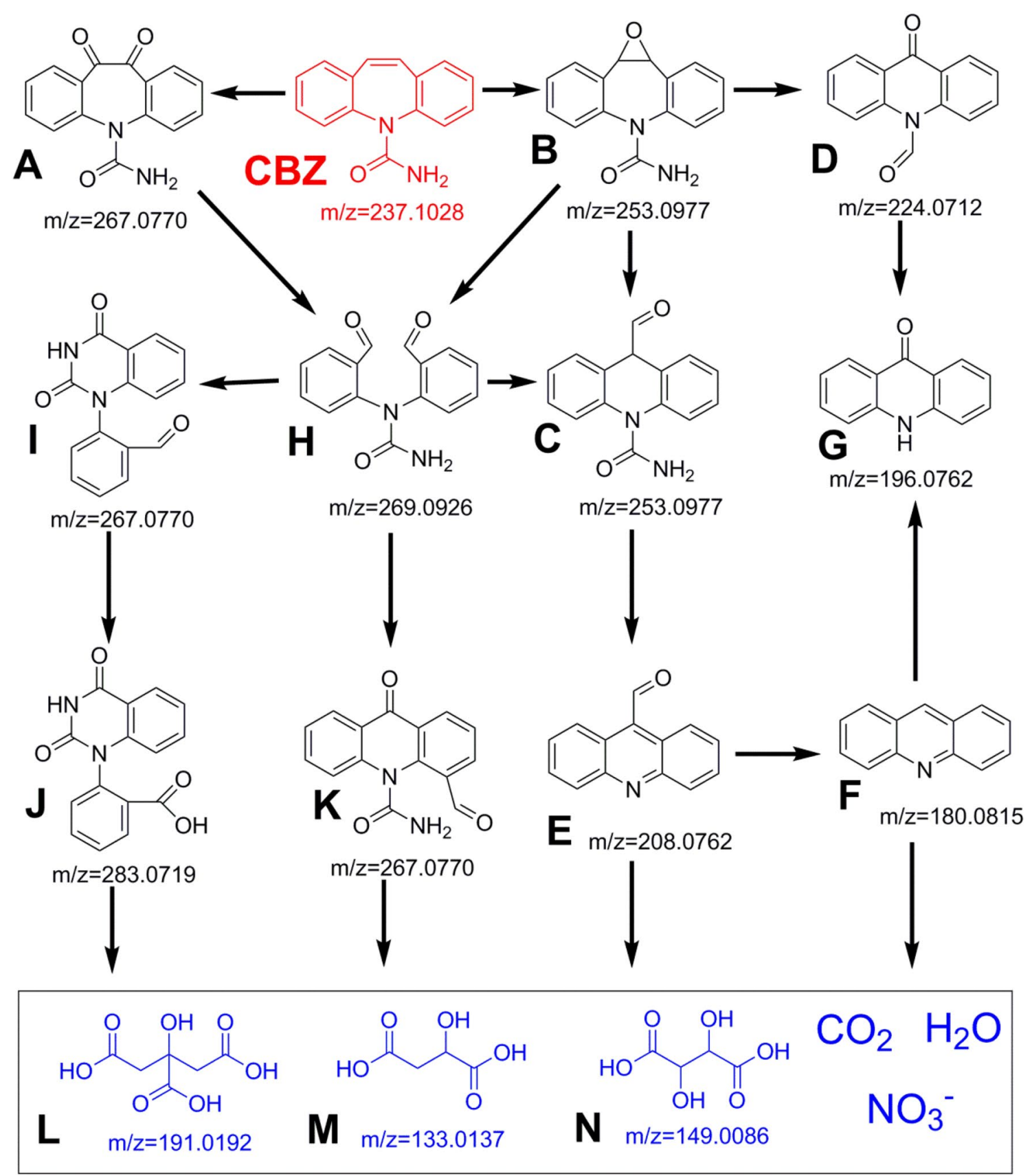

Fig. 11 Proposed CBZ degradation pathway by $\mathrm{FePcCl}_{16}-\mathrm{P} 4 \mathrm{VP} / \mathrm{PAN}$ NFs in the presence of PMS at pH 7 under visible light irradiation $(\lambda>420 \mathrm{~nm})$

$\mathrm{Fe}(\mathrm{IV})=\mathrm{O}+\left(\mathrm{CH}_{3}\right)_{2} \mathrm{SO} \rightarrow\left(\mathrm{CH}_{3}\right)_{2} \mathrm{SO}_{2}$

$2 \mathrm{HO}+2\left(\mathrm{CH}_{3}\right)_{2} \mathrm{SO}+\mathrm{O}_{2} \rightarrow 2 \mathrm{CH}_{3} \mathrm{SO}_{2} \mathrm{H}+\mathrm{HCHO}+\mathrm{CH}_{3} \mathrm{OH}$.

The DMSO was oxidized by the FePcCl16-P4VP/PAN NFs/PMS system under visible light to form $\mathrm{DMSO}_{2}$
(Fig. 7). And no signal of $\mathrm{DMSO}_{2}$ was detected only oxidized by PMS. We infer that $\mathrm{FePcCl}_{16}-\mathrm{P} 4 \mathrm{VP} / \mathrm{PAN}$ NFs contained active $\mathrm{Fe}(\mathrm{IV})=\mathrm{O}$ species.

ESI-MS with a soft MS ionization technique was used to observe high-valency iron-oxo species $(\mathrm{Fe}(\mathrm{IV})=\mathrm{O})[57$, 58]. Figure $8 \mathrm{a}$ and $\mathrm{b}$ shows the chemical molecular structure of $\mathrm{FePcCl}_{16}$-INA and $\mathrm{O}=\mathrm{FePcCl}_{16}$-INA, respectively. 

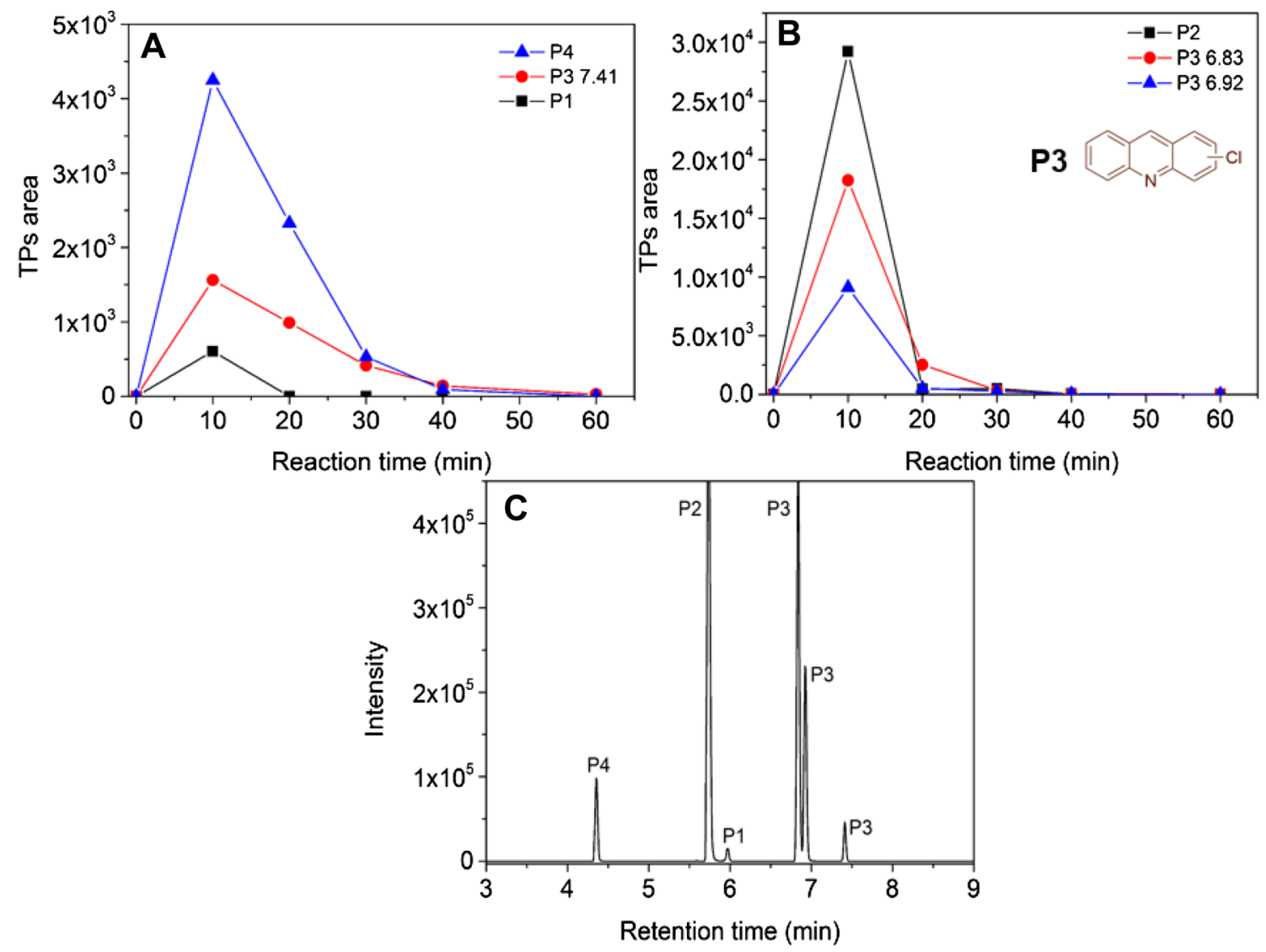

Fig. 12 Reaction over time of main transformation products area (a, b) and TIC of CBZ degradation (c) by $\mathrm{FePcCl}_{16}-\mathrm{P} 4 \mathrm{VP} / \mathrm{PAN}$ NFs in the presence of PMS and $\mathrm{NaCl}$ at $\mathrm{pH} 7$ under visible light irradiation $(\lambda>420 \mathrm{~nm})$

$\mathrm{FePcCl}_{16}$-INA exhibits a series of prominent signals of the molecular peak $\left[\mathrm{Fe}(\mathrm{II}) \mathrm{PcCl}_{16}\right.$-INA] ${ }^{-}$because of elemental chlorine. After PMS addition under visible light, some new signals were detected [the mass spectra is enlarged in Fig. 8c and coincides with the theoretical mass spectrum of $\mathrm{C}_{38} \mathrm{H}_{5} \mathrm{~N}_{9} \mathrm{O}_{3} \mathrm{Cl}_{16} \mathrm{Fe}$ (Fig. 8d)], which conforms to the formulation of $\left[\mathrm{O}=\mathrm{Fe}(\mathrm{IV}) \mathrm{PcCl}_{16}-\mathrm{INA}\right]^{-}$.

The DFT reaction process was calculated by The B3LYP/6-311G method. The length of the Fe-N (4VP) bond $(2.1985 \AA$ ) with PMS was longer than without PMS $(2.1608 \AA$ ) (Fig. S8B and D). The results indicate that the promotion of $\mathrm{O}-\mathrm{O}$ bond cleavage through pyridine ligands to form iron-oxo center. The detailed DFT calculations (Tables S2-S5) show the high electron spin densities at the iron-oxo center (Fig. S8A and C), which achieves electrophilic addition on CBZ and its intermediates.

According to the aforementioned results, a possible photocatalytic mechanism to activate $\mathrm{PMS}$ by $\mathrm{FePcCl}_{16}-\mathrm{P} 4 \mathrm{VP} /$ PAN NFs is shown in Fig. 9. $\mathrm{FePcCl}_{16}$ could be motivated to the excited state $\left(* \mathrm{FePcCl}_{16}\right)$ under visible-light irradiation, which coordinates with the oxygen atoms of PMS to form an $\mathrm{O}-\mathrm{O}$ bond $[39,59]$. The electron-donating effect of pyridine in P4VP promotes the heterolytic cleavage of the $\mathrm{O}-\mathrm{O}$ bond and generates the high-valent iron-oxo $(\mathrm{Fe}(\mathrm{IV})=\mathrm{O})$ species, which is the major active species in this reaction system [60]. Under visible-light irradiation, PMS also could be activated to produce $\mathrm{SO}_{4}^{-}$, which could react with $\mathrm{OH}^{-}$to form $\mathrm{HO}^{\circ}[61] . \mathrm{SO}_{4}^{--}$and $\mathrm{HO}^{\circ}$ are the minor active species which would be captured by $\mathrm{Cl}^{-}$to produce $\mathrm{Cl}^{-}[62]$.

\subsection{CBZ Transformation Products and Pathway by $\mathrm{FePcCl}_{16}-\mathrm{P} 4 \mathrm{VP} / \mathrm{PAN}$ NFs/PMS System Under Visible Light}

During CBZ degradation by the $\mathrm{FePcCl}_{16}$-P4VP/PAN NFs/ PMS system under visible light, a typical intermediate totalion chromatogram (TIC) was obtained according to eleven intermediates $(\mathbf{A}-\mathbf{K})$, which were detected in positive mode (Fig. 10c). Detailed information on the intermediates is shown in Table S6. We provide a comprehensive view of CBZ degradation in Fig. 11. Two isobaric species, $\mathbf{B}$ and $\mathbf{C}$ with empirical formula $\mathrm{C}_{15} \mathrm{H}_{13} \mathrm{~N}_{2} \mathrm{O}_{2}$, and three isobaric species, $\mathbf{A}, \mathbf{I}$ and $\mathbf{K}$, with empirical formula $\mathrm{C}_{15} \mathrm{H}_{11} \mathrm{~N}_{2} \mathrm{O}_{3}$ were formed. Intermediate $\mathbf{B}$ contains one more oxygen atom than 

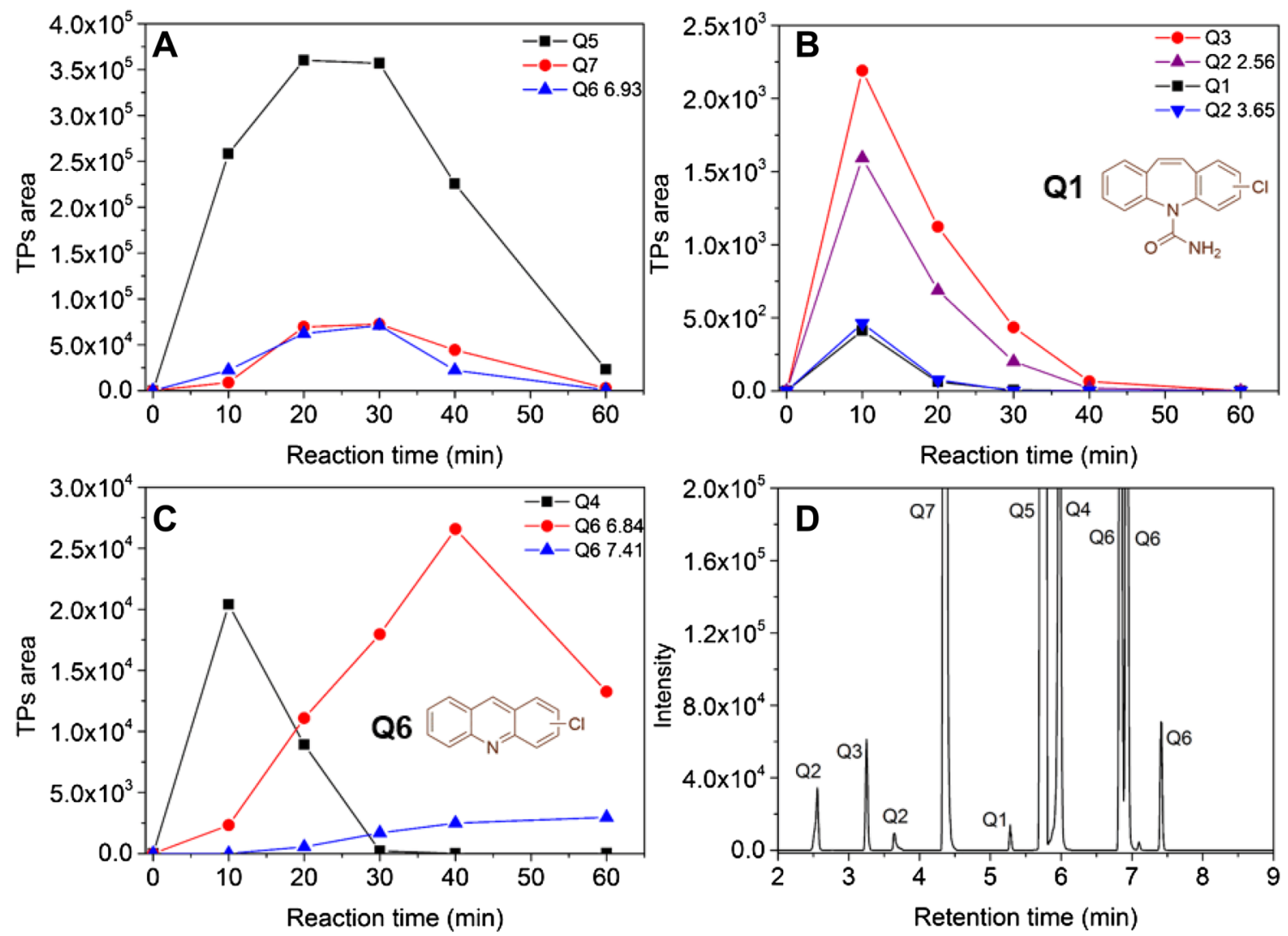

Fig. 13 Reaction over time of main transformation products area (a-c) and TIC of $\mathrm{CBZ}$ degradation (d) in the presence of $\mathrm{PMS}$ and $\mathrm{NaCl}$ at $\mathrm{pH}$ 7 under visible light irradiation $(\lambda>420 \mathrm{~nm})$

the CBZ molecule, whereas the oxidizing species easily attack the reactive 10,11-double bond of the CBZ molecule [63, 64]. Compound A formed from 10-11-dihydroxyl-CBZ by dehydrogenation, which was not observed in this catalytic system [65]. Intermediate B underwent two ring-contraction mechanisms to form intermediates $\mathbf{C}$ and $\mathbf{D}$. Detailed mechanisms have been described in previous studies [66, 67]. Intermediate $\mathbf{H}$ was produced with carboxyl moieties from compound $\mathbf{B}$ by opening the heterocyclic ring [68]. A detailed mechanism has been provided in previous studies, in which compound $\mathbf{H}$ underwent an intramolecular reaction to compound I [69]. I was oxidized further to J. Intermediate $\mathbf{K}$ originated from $\mathbf{H}$ via electrophilic aromatic substitution with intramolecular cyclization. Compound $\mathbf{E}$ formed from compound $\mathbf{C}$ by the loss of a $-\mathrm{CONH}_{2}$ group, and it was oxidized to form compound $\mathbf{F}$. Intermediate $\mathbf{G}$ could result from $\mathbf{D}$ and $\mathbf{F}$ through the removal of a carbonyl group or it could be oxidized, respectively. As the reaction proceeds, the intermediate area increased and then decreased (Fig. 10a, b). After 120 min of treatment, all intermediates were degraded to small acids or were mineralized completely.

\subsection{Comparison of the Removal Efficiency of Chlorine Intermediates With or Without

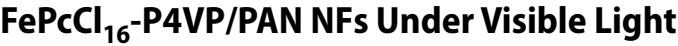

In the chapter on photocatalytic activity, when $\mathrm{NaCl}$ was introduced in this photocatalytic system, the degradation of CBZ was enhanced significantly. The catalytic efficiency of the $\mathrm{FePcCl}_{16}-\mathrm{P} 4 \mathrm{VP} / \mathrm{PAN} \mathrm{NF} / \mathrm{PMS} / \mathrm{NaCl}$ photocatalytic system was more rapid than that of the $\mathrm{PMS} / \mathrm{NaCl}$ photocatalytic system. Although $\mathrm{Cl}^{-}$could enhance the catalytic efficiency, according to other literature [21, 22], chlorine radicals and active chlorine species that formed via the oneelectron oxidation of $\mathrm{Cl}^{-}$caused the occurrence of chlorinated intermediates, which may be more toxic and degrade with more difficulty than the parent. Hence, an investigation of the CBZ transformation products and their evolution processes are very important.

Figures $12 \mathrm{c}$ and $13 \mathrm{~d}$ show that the total-ion chromatogram of CBZ degraded in the presence of PMS and $\mathrm{NaCl}$ with or without $\mathrm{FePcCl}_{16}-\mathrm{P} 4 \mathrm{VP} / \mathrm{PAN}$ NFs. Detailed information on the detected intermediates is listed in Tables S7 and S8. The 
Fig. 14 Proposed CBZ degradation pathway in the presence of PMS and $\mathrm{NaCl}$ with (a) or without (b) $\mathrm{FePcCl}_{16}$-P4VP/ PAN NFs at $\mathrm{pH} 7$ under visible light irradiation $(\lambda>420 \mathrm{~nm})$
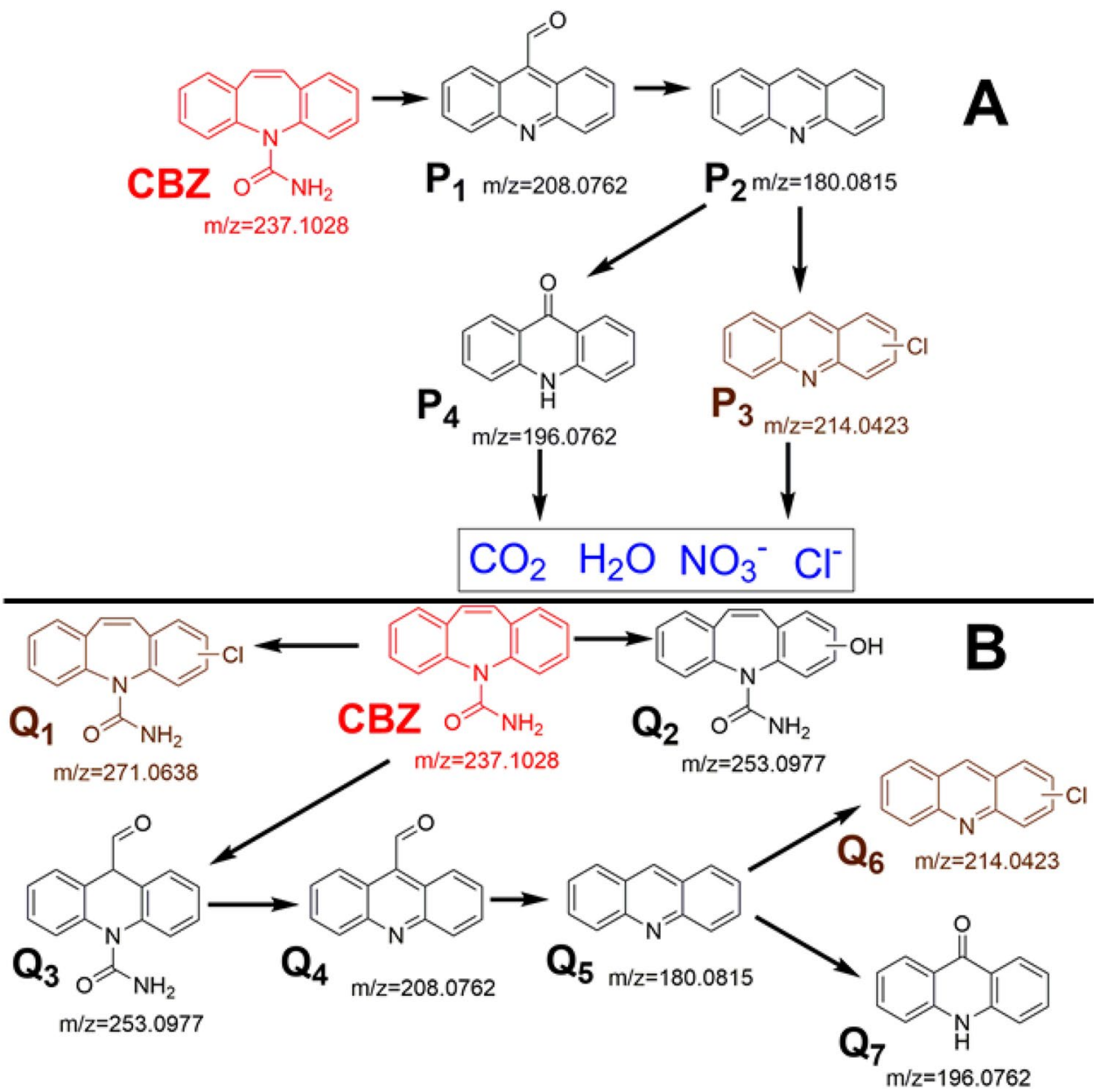

possible degradation pathway of $\mathrm{CBZ}$ in two photocatalytic systems is provided in Fig. $14 \mathrm{a}$ (with $\mathrm{FePcCl}_{16}-\mathrm{P} 4 \mathrm{VP} / \mathrm{PAN}$ NFs) and Fig. $14 \mathrm{~b}$ (without $\mathrm{FePcCl}_{16}$-P4VP/PAN NFs).

Three isomorphisms of organic chloro-derivatives were detected in the two photocatalytic systems. Unfortunately, the specific structure of the three isomorphisms is uncertain. The fate of the chloro-derivatives was not the same in the two photocatalytic systems. In the $\mathrm{FePcCl}_{16}-\mathrm{P} 4 \mathrm{VP} / \mathrm{PAN}$ $\mathrm{NFs} / \mathrm{PMS} / \mathrm{NaCl}$ photocatalytic system, all transformations, including three chloro-derivatives were degraded completely after 40 min reaction (Fig. 12a, b). No other chlorine-containing organic compounds could be detected. In the PMS/ $\mathrm{NaCl}$ photocatalytic system, intermediates that do not contain chlorine were oxidized easily by the radicals (e.g., HO; $\mathrm{SO}_{4}^{-}, \mathrm{Cl}^{\circ}$ ) (Fig. 13a-c). However, chlorine-containing derivatives were also detected after 60 min reaction (Fig. 13c). According to the aforementioned phenomenon, high-valency iron-oxo species $(\mathrm{O}=\mathrm{Fe}(\mathrm{IV}))$ could rapidly destroy chlorinecontaining derivatives, whereas other radicals were unable to achieve this effect.

\section{Conclusions}

A novel heterogeneous photocatalyst $\mathrm{FePcCl}_{16}$-P4VP/PAN NFs was synthesized to activate PMS for refractory contaminant oxidation in high constituent backgrounds, especially for those that contain chlorine ions. The removal of CBZ was enhanced when $\mathrm{NaCl}$ was added to the $\mathrm{FePcCl}_{16}-\mathrm{P} 4 \mathrm{VP} /$ PAN NFs/PMS and the PMS photocatalytic systems. The $\mathrm{PMS} / \mathrm{NaCl}$ photocatalytic system was inefficient to degrade the chlorine-containing intermediates, which are harmful to the aquatic environment. However, the $\mathrm{FePcCl}_{16}$-P4VP/PAN $\mathrm{NF} / \mathrm{PMS} / \mathrm{NaCl}$ photocatalytic system could remove the parent and all transformation products including the chlorinecontaining intermediates promptly and completely, since $\mathrm{Fe}(\mathrm{IV})=\mathrm{O}$ was a critical and effective species in the system. Moreover, $\mathrm{FePcCl}_{16}$ molecules anchored by the pyridyl-containing $\mathrm{P} 4 \mathrm{VP}$, could be excited under visible irradiation to promote the generation of $\mathrm{Fe}(\mathrm{IV})=\mathrm{O}$ active species through a heterolytic cleavage of the $\mathrm{O}-\mathrm{O}$ bond in the presence of PMS. This work provides a new strategy and simple route to treat chlorine-containing wastewater efficiently. 
Acknowledgements This work was supported by the National Natural Science Foundation of China (No. 51703201), and Zhejiang Provincial Natural Science Foundation of China (No. Q19E030051), and the Public Welfare Technology Application Research Project of Zhejiang Province (No. GF18E030003).

Open Access This article is distributed under the terms of the Creative Commons Attribution 4.0 International License (http://creativecommons.org/licenses/by/4.0/), which permits unrestricted use, distribution, and reproduction in any medium, provided you give appropriate credit to the original author(s) and the source, provide a link to the Creative Commons license, and indicate if changes were made.

\section{References}

1. Oh WD, Dong Z, Lim TT (2016) Appl Catal B 194:169

2. Petrie B, Barden R, Kasprzyk-Hordern B (2015) Water Res 72:3

3. Babuponnusami A, Muthukumar K (2014) J Environ Chem Eng 2:557

4. Duan X, Ao Z, Zhou L, Sun H, Wang G, Wang S (2016) Appl Catal B 188:98

5. Cai C, Zhang Z, Liu J, Shan N, Zhang H, Dionysiou DD (2016) Appl Catal B 182:456

6. Guan YH, Ma J, Ren YM, Liu YL, Xiao JY, Lin L, Zhang QC (2013) Water Res 47:5431

7. Li X, Wang Z, Zhang B, Rykov AI, Ahmed MA, Wang J (2016) Appl Catal B 181:788

8. Ren Y, Lin L, Ma J, Yang J, Feng J, Fan Z (2015) Appl Catal B 165:572

9. Guan YH, Ma J, Li XC, Fang JY, Chen LW (2011) Environ Sci Technol 45:9308

10. Ye P, Wu D, Wang M, Wei Y, Xu A, Li X (2018) Appl Surf Sci 428:131

11. Ding Y, Zhu L, Wang N, Tang H (2013) Appl Catal B 129:153

12. Saputra E, Muhammad S, Sun H, Ang HM, Tade MO, Wang S (2013) Appl Catal B 142:729

13. Su S, Guo W, Yi C, Leng Y, Ma Z (2012) Ultrason Sonochem 19:469

14. Song H, Yan L, Ma J, Jiang J, Cai G, Zhang W, Zhang Z, Zhang J, Yang T (2017) Water Res 116:182

15. Sun H, Kwan CK, Suvorova A, Ang HM, Tadé MO, Wang S (2014) Appl Catal B 154-155:134

16. Soltani T, Tayyebi A, Lee BK (2018) Appl Surf Sci 441:853

17. Wang YB, Zhao X, Cao D, Wang Y, Zhu Y (2017) Appl Catal B 211:79

18. Anipsitakis GP, Dionysiou DD, Gonzalez MA (2006) Environ Sci Technol 40:1000

19. Yuan R, Ramjaun SN, Wang Z, Liu J (2011) J Hazard Mater 196:173

20. Wang YR, Chu W (2011) J Hazard Mater 186:1455

21. Ahn YY, Yun ET, Seo JW, Lee C, Kim SH, Kim JH, Lee J (2016) Environ Sci Technol 50:10187

22. Anipsitakis GP, Tufano TP, Dionysiou DD (2008) Water Res 42:2899

23. Costas M (2011) Coord Chem Rev 255:2912

24. Denisov LG, Makris TM, Sligar SG, Schlichting L (2005) Chem Rev 105:2253

25. Meunier B, de Visser SP, Shaik S (2004) Chem Rev 104:3947

26. Sorokin AB (2013) Chem Rev 113:8152

27. Zhang X, Peng T, Yu L, Li R, Li Q, Li Z (2015) ACS Catal 5:504

28. Zhang L, Wang W, Sun S, Sun Y, Gao E, Xu J (2013) Appl Catal B 132-133:315

29. Chen X, Lu W, Xu T, Li N, Qin D, Zhu Z, Wang G, Chen W (2017) Appl Catal B 201:518
30. Colomban C, Kudrik EV, Afanasiev P, Sorokin AB (2014) J Am Chem Soc 136:11321

31. Colomban C, Kudrik EV, Afanasiev P, Sorokin AB (2014) Catal Today 235:14

32. Iliev V, Ileva A (1995) J Mol Catal A 103:147

33. Zhu Z, Lu W, Li N, Xu T, Chen W (2017) Chem Eng J 321:58

34. Zhu Z, Chen Y, Gu Y, Wu F, Lu W, Xu T, Chen W (2016) Water Res 93:296

35. Ni D, Zhang J, Wang X, Qin D, Li N, Lu W, Chen W (2017) Ind Eng Chem Res 56:2899

36. Hu J, Liu H, Wang L, Li N, Xu T, Lu W, Zhu Z, Chen W (2016) Carbon 100:408

37. Lu W, Li N, Bao S, Chen W, Yao Y (2011) Carbon 49:1699

38. Liu M, Xia H, Lu W, Xu T, Zhu Z, Chen W (2016) J Appl Electrochem $46: 583$

39. Wu F, Huang H, Xu T, Lu W, Li N, Chen W (2017) Appl Catal B 218:230

40. Chen X, Lu W, Xu T, Li N, Zhu Z, Wang G, Chen W (2017) Chem Eng J 328:853

41. Lu W, Xu T, Wang Y, Hu H, Li N, Jiang X, Chen W (2016) Appl Catal B 180:20

42. Gao M, Li N, Lu W, Chen W (2014) Appl Catal B 147:805

43. Chen W, Lu W, Yao Y, Xu M (2007) Environ Sci Technol 41:6240

44. Li N, Lu W, Pei K, Yao Y, Chen W (2015) Appl Catal B 163:105

45. Li N, Lu W, Pei K, Yao Y, Chen W (2014) Appl Mater Interfaces 6:5869

46. Nam W, Han HJ, Oh SY, Lee YJ, Choi MH, Han SY, Kim C, Woo SK, Shin W (2000) J Am Chem Soc 122:8677

47. Metz J, Schneider O, Hanack M (1984) Inorg Chem 23:1065

48. Han ZB, Dong YC, Dong SM (2011) J Hazard Mater 189:241

49. Liu JL, Zhang LF, Shi SP, Chen S, Zhou NC, Zhang ZB, Cheng ZP, Zhu XL (2010) Langmuir 26:14806

50. Noh YJ, Park AM, Yeo JS, Kim DY, Kim SS, Na SI (2015) Appl Mater Interfaces 7:25032

51. Ghanbari F, Moradi M (2017) Chem Eng J 310:41

52. Chen MJ, Chu W (2015) Appl Catal B 168:175

53. Zhang BT, Zhang Y, Teng Y (2018) Appl Surf Sci 452:443

54. Deng J, Xu M, Qiu C, Chen Y, Ma X, Gao N, Li X (2018) Appl Surf Sci 459:138

55. Akbari S, Ghanbari F, Moradi M (2016) Chem Eng J 294:298

56. Pang SY, Jiang J, Ma J (2011) Environ Sci Technol 45:3179

57. Afanasiev P, Sorokin AB (2016) Acc Chem Res 49:583

58. Wang Y, Xia H, Sun K, Wu S, Lu W, Feng J, Li N, Pei K, Zhu Z, Chen W (2016) Chem Eng J 304:1000

59. Wang L, Lu W, Wang DN, Xu T, Li N, Zhu Z, Chen H, Chen W (2017) Chem Eng J 330:625

60. Isvoranu C, Wang B, Ataman E, Schulte K, Knudsen K, Knudsen J, Andersen JN, Bocquet ML, Schnadt J (2011) J Phys Chem C 115:20201

61. Xu LJ, Chu W, Gan L (2015) Chem Eng J 263:435

62. Kiwi J, Lopez A, Nadtochenko V (2000) Environ Sci Technol 34:2162

63. Pan Y, Cheng S, Yang X, Ren J, Fang J, Shang C, Song W, Lian L, Zhang X (2017) Water Res 116:254

64. Calza P, Medana C, Padovano E, Giancotti V, Baiocchi C (2012) Rapid Commun Mass Spectrom 26:1687

65. Kaiser E, Prasse C, Wagner M, Bröder K, Ternes TA (2014) Environ Sci Technol 48:10208

66. Chiron S, Minero C, Vione D (2006) Environ Sci Technol 40:5977

67. Li J, Dodgen L, Ye Q, Gan J (2013) Environ Sci Technol 47:3678

68. Zhou Z, Jiang JQ (2015) J Pharm Biomed 106:37

69. Ahmed MM, Chiron S (2014) Water Res 48:229

Publisher's Note Springer Nature remains neutral with regard to jurisdictional claims in published maps and institutional affiliations. 